\title{
Developing Hollow Carbon Balls by Oxidation of Carbon Blacks
}

\author{
Dong-Su Kang, Beom-Jun Kim, Kwang-Ju Lee, Suk-Hwan Kim, Sang-Woo Lee and Jae-Seung Roh* \\ School of Advanced Materials and Systems Engineering, Kumoh National Institute of Technology, Gumi 730-701, Korea
}

\section{Article Info}

Received 13 November 2012 Accepted 28 December 2012

\section{*Corresponding Author \\ E-mail: jsroh@kumoh.ac.kr Tel: +82-54-478-7744}

\section{Open Access}

DOI: http://dx.doi.org/

10.5714/CL.2012.14.1.055

This is an Open Access article distributed under the terms of the Creative Commons Attribution Non-Commercial License (http://creativecommons.org/licenses/ by-nc/3.0/) which permits unrestricted non-commercial use, distribution, and reproduction in any medium, provided the original work is properly cited.

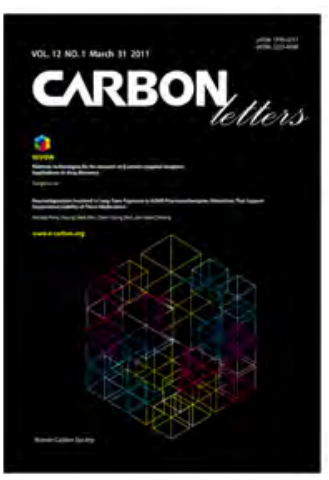

http://carbonlett.org

pISSN: 1976-4251

elSSN: 2233-4998

Copyright $\odot$ Korean Carbon Society

\begin{abstract}
The development of hollow carbon balls by $\mathrm{CO}_{2}$ oxidation of two types of carbon blacks was studied. Super P (SP) and Denka Black (DB) were used for this study. Specific surface area (SSA), structural parameters, and microstructures were examined using Brunauer, Emmett and Teller apparatus, X-ray diffraction spectroscopy, and transmission electron microscope (TEM), respectively. The SSAs of both oxidized carbon blacks increased after oxidation. The SSAs of raw DB and SP were $73 \mathrm{~m}^{2} / \mathrm{g}$ and $60 \mathrm{~m}^{2} / \mathrm{g}$, respectively. Maximum SSAs of oxidized DB and SP were $152 \mathrm{~m}^{2} / \mathrm{g}$ and $253 \mathrm{~m}^{2} / \mathrm{g}$, respectively. The $\mathrm{d}_{002}$ of DB and SP showed almost no change after oxidation. The $\mathrm{L}_{\mathrm{c}}$ of raw DB $(38 \AA)$ and $\mathrm{SP}(19 \AA)$ increased with increasing weight loss. The $\mathrm{L}_{\mathrm{c}}$ of SP increased up to $254 \AA$ at $96 \%$ weight loss. The SSA increased about twice in DB $\left(148 \mathrm{~m}^{2} / \mathrm{g}\right)$ and about four times in SP $\left(254 \mathrm{~m}^{2} / \mathrm{g}\right)$ after 3 $\mathrm{h}$ oxidation compared with the original carbon blacks. Through TEM observation the outer parts of the oxidized carbon blacks showed a rigid shell structure and the inner parts looked empty. Generally it looked like an angular soccer ball, so we named it 'hollow carbon ball.' It is expected that the hollow carbon ball can be used as catalyst supports.
\end{abstract}

Key words: carbon blacks, oxidation, hollow carbon ball, X-ray diffraction spectroscopy, transmission electron microscope

\section{Introduction}

Carbon black is an aggregated substance with globular particles that are used as fillers for macromolecules such as rubbers or plastics, and black pigments for inks or paints $[1,2]$. Since carbon black has been used for almost 100 years, the markets for carbon blacks have changed with their development [3]. The carbon black having chemical rigidity with excellent electric conductivity is used as a cathode material for secondary batteries $[4,5]$. It is possible to improve the characteristics of carbon black by controlling its specific surface area (SSA) and pore structure for use in many fields of application.

Oxidation reactions of carbon-based materials take place preferentially at active sites, and these oxidation reactions are affected by structural inhomogeneity [6-10]. Carbon atoms located in a less ordered area are preferentially removed, more than in an ordered area. Pores are created by such oxidation processes.

This study investigated the development of a process for producing a hollow carbon ball by the oxidation of two types of carbon blacks. SSA and structural parameter changes were examined using Brunauer, Emmett and Teller (BET) apparatus and X-ray diffraction spectroscopy (XRD), respectively. Microstructures of carbon blacks after oxidation were examined using transmission electron microscope (TEM).

\section{Experimental Procedure}

Two types of conductive carbon blacks, Super P(SP, Timcal Graphite) and Denka Black (DB, Denki Kagaku Kogyo Kabushiki Kaishi) were used for this study. Physical properties of these 
Table 1. Physical properties of raw carbon blacks

\begin{tabular}{cccc} 
Carbon blacks & $\begin{array}{c}\text { Particle size } \\
(\mathrm{nm})\end{array}$ & $\begin{array}{c}\text { Specific surface area } \\
\left(\mathrm{m}^{2} / \mathrm{g} \text { by BET }\right)\end{array}$ & $\begin{array}{c}\text { Ash } \\
(\%)\end{array}$ \\
\hline Denka Black & 35 & 69 & 0.01 \\
\hline Super P & 40 & 62 & 0.01 \\
\hline
\end{tabular}

BET: Brunauer, Emmett and Teller.

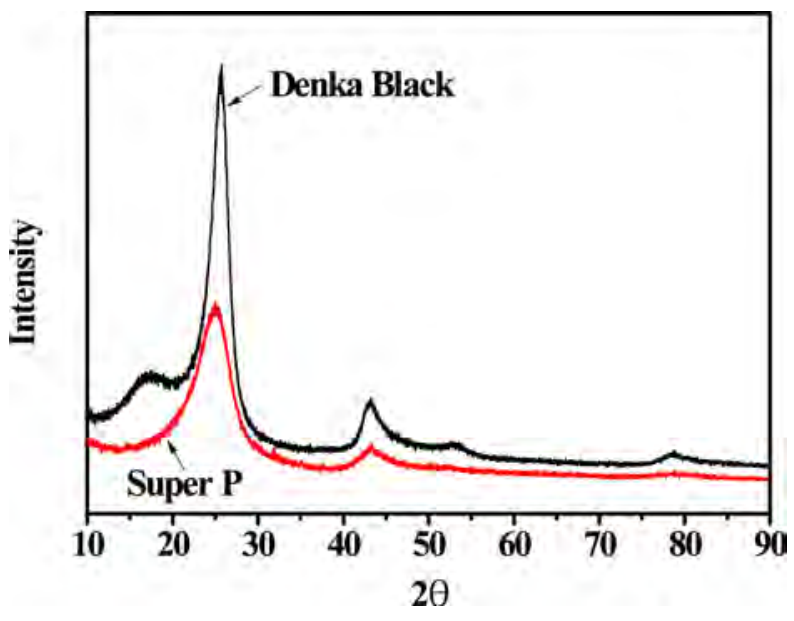

Fig. 1. X-ray diffraction spectroscopy spectra of Denka Black and Super P.

carbon blacks are summarized in Table 1 which was provided by the supplying companies. As shown in Table 1, the particle sizes of SP and DB were $35 \mathrm{~nm}$ and $40 \mathrm{~nm}$, respectively. The SSAs of raw SP and DB were 62 and $69 \mathrm{~m}^{2} / \mathrm{g}$, respectively. Also the DB and SP should have different crystal structure, from Fig. 1. Therefore it was assumed that oxidation rate, SSA, and structural parameters would be shown to be different. The materials went through isothermal oxidation at $600^{\circ} \mathrm{C}$ using a tube furnace in a carbon dioxide gas. A flow rate of $\mathrm{CO}_{2}$ gas was set to $50 \mathrm{~mL} / \mathrm{min}$ and reaction times were set to 1,2 , and $3 \mathrm{~h}$. The SSA data were obtained using BET apparatus at $77 \mathrm{~K}$ by isothermal adsorption curve of nitrogen (ASAP-2010, Micromeritics). Lattice constants and crystallite sizes of the oxidized carbon blacks were obtained from XRD (Rigaku, SWXD, X-MAX, 2000-PC). Overall sizes, shapes, and microstructures of the carbon blacks were observed using TEM (JEM2100, JEOL).

\section{Results and Discussion}

\subsection{SSA and structural parameter}

Weight losses, structural parameters, and SSAs with increasing oxidation time are summarized in Table 2. DB and SP were not changed significantly in their interlayer spacing after oxidation. The $\mathrm{d}_{002}$ of DB and SP were measured to be about $3.5 \AA$ and 3.6 $\AA$, respectively. A crystallite size $\left(\mathrm{L}_{\mathrm{c}}\right)$ of DB $(38 \AA)$ and $\mathrm{SP}(19 \AA$ ) increased with increasing weight loss. The $\mathrm{L}_{\mathrm{c}}$ of SP increased up to $254 \AA$ at $96 \%$ weight loss. It was considered that the increasing of $\mathrm{L}_{\mathrm{c}}$ as the weight loss increased was caused by the preferential removal of carbon atoms located in less ordered areas. Therefore the internal structure of the oxidized carbon blacks became more ordered [7-11]. That means that the $\mathrm{L}_{\mathrm{c}}$ of oxidized carbon blacks increase significantly with increasing weight loss.

The SSAs of original SP $\left(60 \mathrm{~m}^{2} / \mathrm{g}\right)$ and DB $\left(74 \mathrm{~m}^{2} / \mathrm{g}\right)$ were measured to have slightly larger values compare to the values provided by the supplying company. The SSAs of both carbon blacks were increased after oxidation. The SSA increased about twice in DB $\left(148 \mathrm{~m}^{2} / \mathrm{g}\right)$ and about four times in SP $\left(254 \mathrm{~m}^{2} / \mathrm{g}\right)$ after $3 \mathrm{~h}$ of oxidation compared to the original carbon blacks. The increasing of SSAs as the weight loss increased was caused by the removal of atoms located at less ordered areas.

\subsection{Microstructures}

The microstructures of carbon blacks observed using TEM are shown in Figs. 2 and 3. Both carbon blacks exhibited a hollow ball shape after oxidation, where the inside was empty and the outside only had a shell-like composition. The shapes before oxidation were a round ball, while the shape was an angular ball after oxidation. The SP shows the shape of a hollow ball more clearly than DB. The particle size of the oxidized DB is smaller than the oxidized SP even though the weight loss of DB (56\%) was lower than SP (77\%).

Table 2. Weight losses, structural parameters, and SSAs as a function of oxidation time

\begin{tabular}{|c|c|c|c|c|c|}
\hline Carbon blacks & $\begin{array}{l}\text { Oxidation time } \\
\text { (min) }\end{array}$ & $\begin{array}{l}\text { Weight loss } \\
(\%)\end{array}$ & $\begin{array}{l}\mathrm{d}_{002} \\
(\AA)\end{array}$ & $\begin{array}{l}\mathrm{L}_{\mathrm{c}} \\
(\AA)\end{array}$ & $\begin{array}{l}\text { Specific surface area } \\
\left(\mathrm{m}^{2} / \mathrm{g} \text { by BET }\right)\end{array}$ \\
\hline \multirow{4}{*}{ Denka Black } & 0 & 0 & 3.49 & 38 & 74 \\
\hline & 60 & 13 & 3.49 & 35 & 138 \\
\hline & 120 & 35 & 3.50 & 36 & 152 \\
\hline & 180 & 56 & 3.49 & 37 & 148 \\
\hline \multirow{4}{*}{ Super P } & 0 & 0 & 3.61 & 19 & 60 \\
\hline & 60 & 49 & 3.59 & 20 & 186 \\
\hline & 120 & 77 & 3.57 & 20 & 240 \\
\hline & 180 & 96 & 3.55 & 21 & 254 \\
\hline
\end{tabular}

SSAs: specific surface areas, Brunauer, Emmett and Teller. 

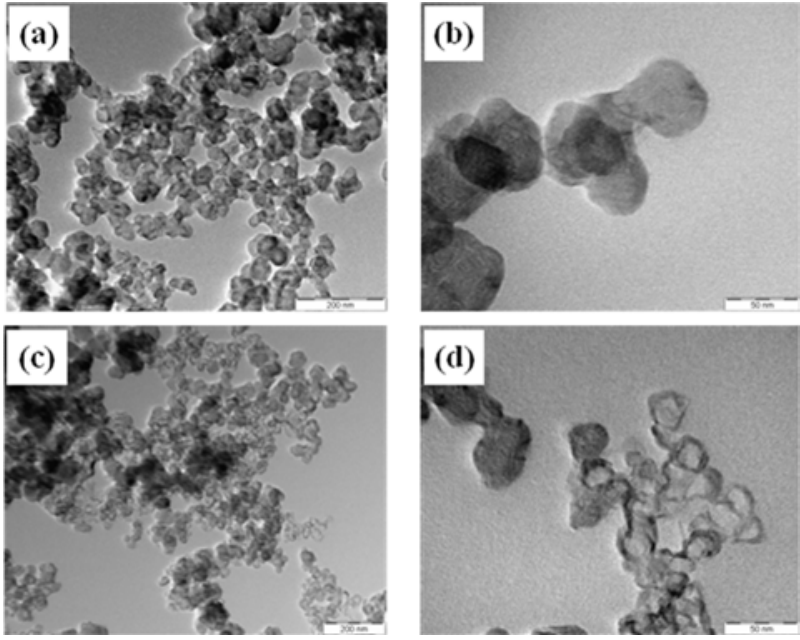

Fig. 2. Transmission electron microscope photos of raw and oxidized Denka Blacks: (a) raw ( $\times 50000)$, (b) raw $(\times 500000)$, (c) oxidized to $56 \%$ weight loss $(\times 50000)$, and (d) oxidized to $56 \%$ weight loss at $600^{\circ} \mathrm{C}$ after 3 $\mathrm{h}$ in carbon dioxide gas $(\times 500000)$.
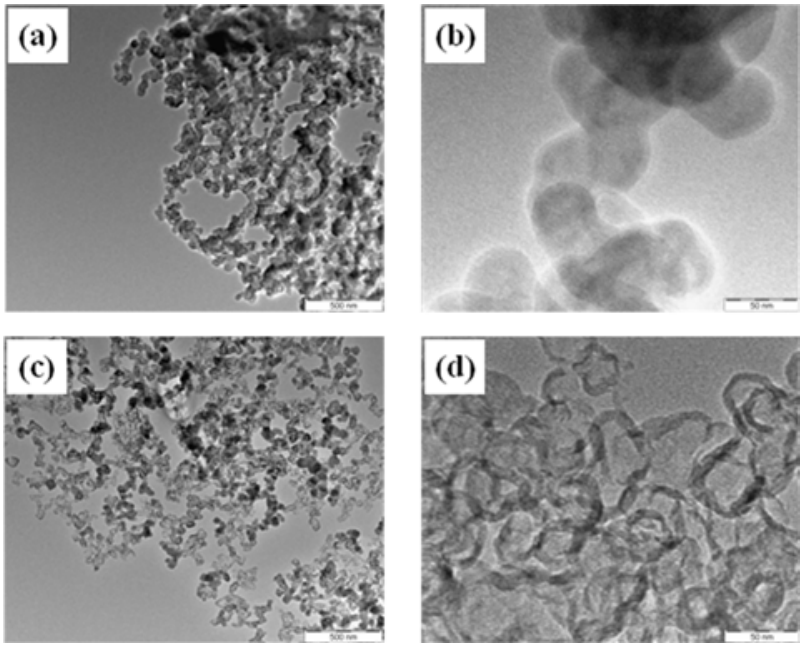

Fig. 3. Transmission electron microscope photos of raw and oxidized Super P: (a) raw $(\times 50000)$, (b) raw $(\times 500000)$, (c) oxidized to $77 \%$ weight loss ( $\times 50000)$, and (d) oxidized to $77 \%$ weight loss at $600^{\circ} \mathrm{C}$ after $2 \mathrm{~h}$ in carbon dioxide gas $(\times 500000)$

Through TEM observation the outer parts of the oxidized carbon blacks showed a rigid shell and the inner parts looked empty. Generally it looked like an angular soccer ball, so we called it 'hollow carbon ball.' The overall thickness of the rigid shell of the oxidized DB was about 2-5 $\mathrm{nm}$ and the diameter of the inner empty space was about 10-20 $\mathrm{nm}$. Also the overall thickness of the rigid shell of oxidized SP was about $8 \mathrm{~nm}$ and the diameter of the inner empty space was about $20-30 \mathrm{~nm}$. It is expected that the hollow carbon ball can be used as catalyst supports.

\section{Conclusions}

Development of a hollow carbon ball by the oxidation of two types of carbon blacks was studied and the following conclusions can be drawn from the results.

The SSA of raw DB and SP were $73 \mathrm{~m}^{2} / \mathrm{g}$ and $60 \mathrm{~m}^{2} / \mathrm{g}$, respectively. The maximum SSAs of oxidized DB and SP were $152 \mathrm{~m}^{2} / \mathrm{g}$ and $253 \mathrm{~m}^{2} / \mathrm{g}$, respectively. The $\mathrm{d}_{002}$ of DB and SP showed almost no change after oxidation. The $\mathrm{L}_{\mathrm{c}}$ of raw DB (38 $\AA)$ and SP (19 $\AA)$ were increased with increasing weight loss. The $\mathrm{L}_{\mathrm{c}}$ of SP increased up to $254 \AA$ at $96 \%$ weight loss. The SSA increased about twice in DB $\left(148 \mathrm{~m}^{2} / \mathrm{g}\right)$ and about four times in SP $\left(254 \mathrm{~m}^{2} / \mathrm{g}\right)$ after $3 \mathrm{~h}$ oxidation, compared to the original carbon blacks.

Through TEM observation the outer parts of the oxidized carbon blacks showed a rigid shell and the inner parts looked empty. Generally it looked like an angular soccer ball, so we called it 'hollow carbon ball.' It is expected that the hollow carbon ball can be used as catalyst supports.

\section{Acknowledgements}

This paper was supported by the Research Fund of Kumoh National Institute of Technology.

\section{References}

[1] Leblanc JL. Flowing from art to science. Eur Rubber J, 171, 33 (1989).

[2] Viricelle JP, Riviere B, Pijolat C. Optimization of $\mathrm{SnO}_{2}$ screenprinting inks for gas sensor applications. J Eur Ceram Soc, 25, 2137 (2005). http://dx.doi.org/10.1016/j.jeurceramsoc.2005.03.020.

[3] Lin Y, Smith TW, Alexandridis P. Adsorption of a rake-type siloxane surfactant onto carbon black nanoparticles dispersed in aqueous media. Langmuir, 18, 6147 (2002). http://dx.doi.org/10.1021/ la011671t.

[4] Auer E, Freund A, Pietsch J, Tacke T. Carbons as supports for industrial precious metal catalysts. Appl Catal A, 173, 259 (1998). http:// dx.doi.org/http://dx.doi.org/10.1016/S0926-860X(98)00184-7.

[5] Dalas E, Vitoratos E, Sakkopoulos S, Malkaj P. Polyaniline/zeolite as the cathode in a novel gel electrolyte primary dry cell. J Power Sources, 128, 319 (2004). http://dx.doi.org/http://dx.doi. org/10.1016/j.jpowsour.2003.09.062.

[6] Robau-Sanchez A, Aguilar-Elguezabal A, de la Torre-Saenz L, Lardizabal-Gutierrez D. Radial distribution of porosity in spherical activated carbon particles. Carbon, 41, 693 (2003). http://dx.doi. org/http://dx.doi.org/10.1016/S0008-6223(02)00383-4.

[7] $\mathrm{Hu} Y Q$, Nikzat H, Nawata M, Kobayashi N, Hasatani M. The characteristics of coal-char oxidation under high partial pressure of oxygen. Fuel, 80, 2111 (2001). http://dx.doi.org/http://dx.doi. org/10.1016/S0016-2361(01)00086-2.

[8] Rafsanjani HH, Jamshidi E, Rostam-Abadi M. A new mathematical solution for predicting char activation reactions. Carbon, 40, 1167 (2002). http://dx.doi.org/http://dx.doi.org/10.1016/S0008-6223 (01)00265-2.

[9] Roh JS, Kim SH, Structural study of the oxidized high modulus carbon fiber using laser raman spectroscopy, Carbon Lett, 10, 38 (2009). http://dx.doi.org/10.5714/CL.2009.10.1.038.

[10] Roh JS, Suhr DS, A structural study of the activated carbon fibers as a function of activation degrees, Carbon Lett, 5, 51-54 (2004). 